\title{
PEMBELAJARAN PARIKAN (PANTUN JAWA) DALAM KEARIFAN LOKAL BUDAYA JAWA SEBAGAI PEMBENTUK KAREAKTER SISWA
}

\author{
Oleh: Tri Indah Prasasti \\ (Pascasarjana Universitas Negeri Medan) \\ Indah_dheniez@yahoo.co.id
}

\begin{abstract}
Abstrak
Definisi parikan ialah tradisi lisan, budaya lisan dan adat lisan adalah pesan atau kesaksian yang disampaikan secara turun-temurun dari satu generasi ke generasi berikutnya. Pesan atau kesaksian itu disampaikan melalui ucapan, pidato, nyanyian, dan dapat berbentuk pantun, cerita rakyat, nasehat, balada, atau lagu. Dari segi makna dan fungsi parikan ada beragam parikan dalam masyarakat jawa yaitu sebagai ekspresi jiwa susah, sebagai control sosial, sebagai sindiran, sabagai ekspresi ilmu sejati, sebagai estetika gending dan lainnya. Parikan banyak digunakan sebagai pementasan atau sebagai hiburan berbeda dengan pantun yang digunakan sebagai pesan sosial dan untuk kebutuhan politik pada saat kampanye. Misalnya parikan digunakan untuk gara-gara wayang kulit, dagelan kethoprak, kentrung, dan jathilan. Pada tembang Jawa terdapat nilai-nilai moral sebagai pembentuk karakter siswa yang dapat diterapkan dalam kehidupan sehari-hari, terutama dalam membentuk siswa yang berkarakter. Hal itu pun berkaitan dengan konsep kearifan lokal yang kini mulai sering kita dengar.
\end{abstract}

\section{PENDAHULUAN}

Masuknya teknologi dari negara maju ke negara berkembang ikut masuk kebudayaan ke negara maju tersebut yang sangat memengaruhi perilaku negara-negara berkembang. Dengan demikian bangsa Indonesia yang termasuk masyarakat Suku Jawa mengalami pergeseran budaya. Kebergeseran budaya dengan teknologi membuat hilangnya keaslian budaya pada masyarakat. Budaya tersebut di dalamnya termasuk dalam budaya parikan yang sejak zaman dahulu menjadi salah satu budaya yang sama-sama dirasakan.

Parikan adalah bunyi yang terdiri atas dua ukara (bagian) yaitu untuk narik kawigaten, maksudnya adalah menarik perhatian dan yang kedua adalah minangka isi (yaitu sebagai isi). Parikan merupakan karya manusia yang seperti pantun tapi hanya terdiri dari dua larik. Parikan menggunakan purwakanthi swara yaitu dasar untuk menunjukkan perhitungan dalam wanda atau suku kata. Parikan adalah bagian dari tradisi lisan, budaya lisan dan adat 
lisan yang didefinisikan sebagai adalah pesan atau kesaksian yang disampaikan secara turuntemurun dari satu generasi ke generasi berikutnya. Pesan atau kesaksian itu disampaikan melalui ucapan, pidato, nyanyian, dan dapat berbentuk pantun, cerita rakyat, nasehat, balada, atau lagu.

Parikan ini mengandung banyak pesan moral yang dapat dijadikan pembelajaran siswa sebagai pemebentukan karekater siswa, karena di dalam parikan banyak pesan-pesan yang menyampaikan tentang toleransi, rendah diri, pemikiran yang kritis, religius, dan lain sebagainya.

\section{PEMBAHASAN}

\section{Parikan (Pantun Jawa)}

Pantun merupakan satu di antara sekian banyak genre kesusastraan yang lahir dan berkembang di nusantara. Pada mulanya, istilah pantun ini berasal dari bahasa Minangkabau "patuntun" yang berarti penuntun. Namun ternyata, istilah pantun ini pun dikenal juga di kalangan masyarakat Suku Jawa, Sunda, Batak, dan Melayu. Dalam masyarakat Suku Jawa, pantun dikenal dengan istilah "parikan." Dalam masyarakat Sunda dikenal dengan sebutan "paparikan". Sementara masyarakat Batak mengenal pantun dengan istilah "umpasa" (dibaca uppasa). Masih tentang pantun, dalam bahasa Melayu, pantun dikenal dengan istilah "quatrain".

Definisi parikan ialah tradisi lisan, budaya lisan dan adat lisan adalah pesan atau kesaksian yang disampaikan secara turun-temurun dari satu generasi ke generasi berikutnya. Pesan atau kesaksian itu disampaikan melalui ucapan, pidato, nyanyian, dan dapat berbentuk pantun, cerita rakyat, nasehat, balada, atau lagu. Pada cara ini, maka mungkinlah suatu masyarakat dapat menyampaikan sejarah lisan, sastra lisan, hukum lisan dan pengetahuan lainnya ke generasi penerusnya tanpa melibatkan bahasa tulisan. Istilah parikan memang asli Jawa. Parikan identik dengan pantun dalam bahasa Indonesia. Karena genre ini memuat banyak pari, kemudian disebut dengan parikan (artinya; memuat banyak pari). Di dalamnya terkandung sampiran dan isi (Endraswara, 2005:59). Parikan tersebut merepresentasikan pendidikan karakter di dalamnya. Pendidikan karakter yang muncul dalam parikan adalah salah satu alternatif pembentukan pendidikan karakter pada anak-anak di sekolah.

Parikan adalah bunyi yang pada bagian pertama sebagai sampiran atau penentu suara, kedua adalah berupa isi. Diungkap dalam bahasa Jawa, Parikan yaiku 'unen-unen rong perangan perangan (bagian) kapisan kanggo pancandan (sampiran) (kanggo pentokaning 
swara), dene perangan kapindho mawa teges (merupakan isi) kang dikarepake.' Parikan adalah bunyi yang terdiri atas dua bentuk yang pertama untuk menarik perhatian yang berupa sampiran dan yang kedua berupa isi.

Peran pantun (parikan) sebagai alat pemelihara bahasa, pantun berperan sebagai penjaga fungsi kata dan kemampuan menjaga alur berfikir. Pantun melatih seseorang berfikir tentang makna kata sebelum berujar. Ia juga melatih orang berfikir asosiatif, bahwa suatu kata bisa memiliki kaitan dengan kata yang lain. Secara sosial pantun memiliki fungsi pergaulan yang kuat, bahkan hingga sekarang. Di kalangan pemuda sekarang seharusnya, kemampuan berpantun biasanya dihargai. Pantun menunjukkan kecepatan seseorang dalam berfikir dan bermain-main dengan kata. Parikan ada dua warna, (dua jenis) yaitu:

1. Terdiri atas 2 kalimat yang bersajak.

2. Saben saukara kedadean saka rong gatra (larik). Dalam hal ini adalah bentuk parikan panjang

3. Ukara pertama berupa purwaka (sampiran), ukara kedua berupa uwose (isi).

Parikan Sebuah Idola Jawa Parikan merupakan kata pantun (bahasa jawa krama) sering diterjemahkan ke dalam bahasa jawa ngoko menjadi pari. Artinya berbagai hal tentang pari. Parikan berarti sejajar dengan pantun, maka di dalamnya harus ada sampiran (ancangancang) bicara, dan isi (kandungan) makna berikutnya. Karena parikan ini termasuk atau merupakan tradisi lisan rakyat jadi tidak jelas siapa penciptanya atau anonim. Hubungan sampiran dan isi sejajar tak ada yang lebih dominan atau penting, keduanya saling mengisi membentuk sebuah estetika. Dengan kata lain pantun dan parikan sebenarnya memiliki ciriciri yang senada. Keduanya memiliki struktur sampiran dan isi. Sampiran adalah kata-kata awal yang membutuhkan jawaban (isi). Sampiran dan isi harus selaras bunyi vokal dan konsonannya.

Parikan merupakan genre puisi rakyat yang khas, meskipun demikian parikan tergolong puisi jawa tradisional tembang para, artinya aturan yang digunakan tidak terlalu ketat. Parikan juga sering digunakan dalam pentas seni yaitu gara-gara wayang kulit, dagelan kethoprak, kentrung, jathilan, dan sebagainya yang dimanfaatkan sebagai wahana ekspresi. Parikan cocok sebagai konsumsi kejiwaan. Orang Jawa sudah membicarakan dan memanfaatkan parikan dalam ragam seni, sehingga parikan semakin digemari dan menjadi idola. Orang yang mendengarkan pun akan merasa adanya getaran-getaran jiwa yang menggores. 
Berkait dengan pendidikan karakter, Hidayatullah (2010:13) memaparkan bahwa pendidikan karakter berkait dengan kualitas atau kekuatan mental seseorang yang berbeda dengan orang lain. Lebih jauh, Baedhowi mengungkapkan bahwa pendidikan karakter secara universal, antara lain (1) kedamaian (peace), (2) menghargai (respect), (3) kerja sama (cooperation), (4) kebebasan (freedom), (5) kebahagiaan (happines), (6) jujur (honesty), (7) kerendahan hati (huminity), (8) kasih sayang (love), (9) tanggung jawab (responsibility), dan (10) kesederhanaan (simplicity), (11) toeleransi (tolerance), dan (12) persatuan (unity) (Baedhowi, 2010:3). Berikut dipaparkan contoh parikan yang didalamnya merepresentasikan pendidikan karakter (Daryanto, 1999:143-144).

\subsection{Parikan Jawa Sebagai Sumber Kearifan Lokal dan Pembentuk Karakter Siswa}

Dari segi makna dan fungsi parikan ada beragam parikan dalam masyarakat jawa yaitu sebagai berikut:

\section{Manuk tuhu menclok pager}

Yen sinau mesthi pinter

Ngasah arit nganthi landhep

Dadi murid kudu sing sregep

Jemek-jemek gulo jawa

Aja sok ngenyek karo kanca

Parikan Manuk tuhu menclok pager, Yen sinau mesthi pinter (burung Tuhu hinggap di pagar, jika belajar, pasti pintar) merepresentasikan pendidikan karakter kegigihan dalam belajar. Jika belajar, pastilah pintar. Filosofi tersebut sangat dalam sebab saat ini kebanyakan muridmurid lebih suka nge-game daripada belajar. Mereka -para murid-- lebih disibukkan dengan dunia maya (facebook-an, chatting-an, BBM-an) yang sekarang sedang menjadi trend di Indonesia. Jika tidak mengikuti trend seperti itu, mereka dianggap jadul/ketinggalan zaman, kuper. Parikan Ngasah arit nganthi landhe, Dadi murid kudu sing sregep (Mengasah sabit sampai tajam, Jadi murid harus rajin). Parikan tersebut merepresentasikan pendidikan karakter yang berkait dengan kerajinan/keuletan dalam menimba ilmu di sekolah. Parikan Jemek-jemek gulo jawa, Aja sok ngenyek karo kanca (becek-becek gula jawa, jangan menghina sesama teman) merepresentasikan pendidikan karakter toeleransi dengan sesama teman. Dengan begitu, sesama teman mereka tidak mudah bermusuhan/bertengkar satu sama 
lain. Selain itu, pendidikan karakter rasa persatuan dengan sesama teman pun muncul dalam parikan tersebut.

2. Sebagai ekspresi jiwa susah

Contoh :

Kaya ngapa rasane tape

Kaya bengkoang ginawe rawon

Kaya ngapa rasane wong ora duwe

Kaya wayang gawe lakon

Parikan di atas menggambarkan keadaan jiwa seseorang yang kurang mampu. Dia amat merasakan keberadaan dirinya yang sangat kekurangan berbagai hal yang diibaratkan seperti wayang yang dibuat satu lakon dalam pementasan wayang yang harus ikut setiap gerakan sang dhalang. Yang menurutnya itu sudah tidak bisa diubah lagi, ungkapan semacam Ini merupakan pelarian agar menyenangkan diri lewat parikan.

3. Sebagai kontrol sosial

Contoh:

Tak ibaratna lampune lilin

Mobat mabit kesilir angin

Ora gampang dadi pemimpin

Dikoreksi rakyat sing miskin

Perikan tersebut ditujukan kepada pemimpin bangsa yang seharusnya simpati terhadap dunia bawah yang selalu kekurangan. Batas kesenjangan ekonomi biasanya yang menjadi bahan pijakan. Hal ini menunjukkan sebuah ekspresi protes sosial. Fungsi folklor itu amat penting sebagai alat kontrol sosial.

4. Sebagai sindiran

Contoh:

Cecak kecemplung lenga

Tewas macak ora sida lunga

Theklek kecemplung kalen

Tinimbang golek aluwung balen 
Berdasarkan makna dan fungsinya parikan tersebut merupakan sastra lisan masih mempunyai fungsi yang jelas dalam masyarakat. Namun demikian untuk memahami fungsi parikan yang tergolong sastra lisan memerlukan pemikiran yang kritis. Pemikiran kritis inilah yang diharapkan kepada siswa agar mampu mengungkapkan makna sindiran yang terdapat pada parikan tersebut.

5. Sebagai ekspresi ilmu sejati

Parikan juga ada kalanya membeberikan ilmu sejati yakni tentang kesempurnaan hidup.

Contoh parikan kentrung :

Ten pisah maring wong lanang

Randha durung peputra

Tindakane maring gunung

Welanjar durung akrama

Siti pinendhem sajroning bumi

Banyu kelem sajroning toya

Prawan ayu rupane

Parikan tersebut merupakan bentuk ilmu tua banyak menggunakan parikan yang menuju pada pencapaian hidup purna. Melalui perumpaman (isbat). Si kesut mengitari jagat dan si buta menghitung bintang adalah gambaran hidup manusia. Dengan bekal budi dan nalar akan dapat menyebabkan orang bisa tahu ilmu wadhag yaitu kosmologi jawa tentang alam semesta. Kosmologi merupakan ilmu yang mempelajari struktur dan sejarah alam semesta dalam skala besar. Orang tuna rungu memikul air dan mencari api merupakan gambaran orang jawa yang mencapai pada ngelmu yang sejati. Pada waktu mencari ilmu harus siap wadhah atau batin yang bersih karena bekal kebersihan atau kesucian merupakan bekal awal yang harus dibawa agar mudah dalam mencari ilmu.

6. Sebagai estetika gending

Fungsinya untuk memperindah alunan gending Sinom parijatha. Parikan ini sering dimanfaatkan untuk senggakan atau selingan dalam gending. Senggakan semacam itu selain 
dapat memperindah nuansa gending juga akan memercikan ajaran-ajaran kejawen. Makna dari senggakan tersebut merupakan ajaran moral jawa yaitu :

a. Manusia jangan mempersulit pihak lain dalam konteks diajak ora gelam ditinggal golong koming maksudnya adalah ketika orang diajak tidak mau ditinggal sakit hati, seharusnya manusia jangan pernah mempersulit pihak lain jika diajak seseorang jawab dengan jelas ya dan tidaknya jangan mempersulit atau membingungkan orang lain.

b. Diharapkan agar mempunyai jiwa yang sabar.

c. Manusia yang telah malang melintang, hal ini dimaksudkan untuk menggugah semangat bahwa orang yang berusaha keras akan memetik hasilnya yang diungkapkan dalam senggakan ngana aja ngana.

d. Merujuk pada sikap manusia hendaknya tahu diri. Hal ini dimaksudkan bahwa hubungan sosial orang Jawa sebaiknya dijaga dengan ungkapan yang mengisyaratkan bahwa hubungan sosial Jawa amat penting.

e. Sebagai penutup bicara seorang pranatacara. Orang Jawa yang berbicara di depan umum biasanya selalu anoraga (merendahkan diri). Sikap ini dimanifestasikan ke dalam parikan lisan yang khas.

Sebagai contoh:

parikan suminten sura menggala, cekap semanten atur kula,

kemudian dilanjutkan dengan parikan, salah satu contohnya sebagai berikut :

Kupat kecemplung santen

Menawi lepatnyuwun pangapunten

Kupat tercebur santan

Jika salah mohon maaf

Parikan tersebut dalam konteks pilihan yang kata yang digunakan oleh para pranatacara cukup khas dan bermodus pada kata kupat. Kupat (ketupat) adalah bahan makanan yang dibungkus janur. Kupat juga sering muncul di tradisi lebaran, yang berkaitan pula dengan permohonan maaf. Dengan demikian pemakainan kata kupat tersebut secara kultural memang sangat mendukung estetika. Ungkapan permohonan maaf seperti itu seakanakan telah menjadi bumbu di akhir pidato seorang pranata cara. 


\subsection{Tembang Jawa Sebagai Sumber Kearifan Lokal dan Pembentuk Karakter Siswa}

Makalah ini dipilih makna istilah tembang yang terdapat dalam Kamus Besar Bahasa Indonesia (KBBI). Dalam KBBI, kata tembang memiliki dua makna, yang pertama bermakna syair yang diberi berlagu (untuk dinyanyikan), nyanyian, yang kedua bermakna puisi. Jadi, makna tembang Jawa dalam makalah ini adalah lagu Jawa sesuai pemaknaan dalam KBBI. Seperti yang ingin dicapai dalam tujuan penulisan, yaitu mengembangkan karakter diri pribadi menuju karakter bangsa melalui terjemahan syair-syair tembang Jawa dalam pengajaran bahasa dan sastra Indonesia.

Pada tembang Jawa terdapat nilai-nilai moral yang dapat diterapkan dalam kehidupan sehari-hari, terutama dalam membentuk siswa yang berkarakter. Hal itu pun berkaitan dengan konsep kearifan lokal yang kini mulai sering kita dengar.

Menurut Amir (2013), sastra lisan menyimpan kearifan lokal (local wisdom), kecendikiaan tradisonal, pesan-pesan moral, dan nilai sosial dan budaya. Semua itu tumbuh, berkembang, dan diwariskan dalam masyarakat sastra itu secara lisan. Ketika kita berbicara tentang pembangunan karakter bangsa, mestinya sastra lisan menjadi salah satu suber karakter bangsa karena karakter yang disimpan dalam sastra lisan itu sesuai dengan konteks sosial, agama, dan lingkungan kita.

Sebenarnya, ketika berbicara tentang kearifan lokal, penulis menawarkan sebuah wacana tentang pengajaran sastra di sekolah, dalam hal ini di SMP. Pengajaran sastra yang dimaksud adalah pengajaran sastra berbasis kearifan lokal, yaitu pengajaran sastra yang tidak hanya menggunakan pengalaman hidup masyarakat Jawa (dalam tembang Jawa) saja seperti yang akan dibahas dalam makalah ini, tetapi juga pengalaman hidup masyarakat (dalam bentuk tembang) daerah lain yang populer di kalangan anak-anak atau remaja.

Berkaitan dengan kearifan lokal, sebuah tembang Jawa dapat dijadikan contoh. Misalnya, lagu Tombo Ati.

a. Perhatikan penggalan syair "Tombo Ati" berikut ini.

Tombo ati iku lima ing wernane

Ingkang dhingin maca Quran sak maknane

Kaping pindho sholat sunat lakonana

Kaping telu wong kang sholeh kumpulana

Kaping papat kudu weteng ingkang luwe 
Kaping limo dzikir wengi ingkang suwe

Sak kabehe sapa bisa anglakoni

Insya Allah huta'ala ngijabahi

Gusti Allah kang kuwasa

Gawe kewan lan manungsa

Gawe srengenge lan mbulan

Gawe bumi lan wit-witan...

Artinya:

Obat hati itu ada lima macam

Yang pertama membaca Quran dan memaknainya

Kedua menjalankan sholat sunat

Ketiga kumpul dengan orang sholeh

Keempat perut harus lapar

Kelima dzikir malam yang lama

Seluruhnya bagi yang bisa melakukan

Insya Allah huta'ala mengabulkan

Gusti Allah Maha Kuasa

Menciptakan hewan dan manusia

Menciptakan matahari dan bulan

Menciptakan bumi dan pepohonan

Pengalaman religius dapat dijadikan tema penulisan puisi karena setiap siswa bisa mendapatkannya setiap saat. Syair tersebut menyampaikan pesan religius yang dapat menyarankan kita untuk melaksanakan apa yang diperintahkan oleh yang Maha Kuasa. Syair tersebut dapat menumbuhkan karakter siswa yang religius yang selalu ingat kepada Sang Maha Pencipta, sehingga siswa dapat melakukan suatu tindakan atau perbuatan yang tidak semena-mena.

b. Perhatikan syair lagu berikut ini. 
Turi-Turi Putih

Turi-turi putih ditandur neng kebon agung

Cleret tiba nyemplung kepundhung kebange apa

Mbok ira mbok ira mbo ira kembange apa

Kembang-kembang menur

Sing dakpilih kembange menur

Ayo kanca padha syukur

Kanggo sangu ning alam kubur

Mbo ira mbo ira mbo ira kembange apa

Kembang-kembang mlathi

Sing dakpilih kembang mlathi

Sing dakphilih kembang mlathi

Ayo kanca padha bekti

Sungkem marang ibu pertiwi

Artinya:

bunga turi putih di tanam di kebun besar

Celeret jatuh tercebur kepundhung bunga apa

Mbo ira-mbo ira mbo ira bunga apa

Bunga-bunga menur

Yang kupilih bunga menur

Ayo teman syukur bersama

Sebagai bekal di alam kubur

Mbok ira mbo ira mbo ira bunga apa

Bunga-bunga melati

Yang kupilih bunga melati

Yang kupilih bunga melati

Ayo teman sama-sama berbakti

Sujud kepada ibu pertiwi" 
“Turi-turi putih" menyimbolkan makna kesucian hati, terkandung pula makna religius, dan cinta tanah air yang menjadi dasar sikap toleransi siswa.

\section{SIMPULAN}

Sejak lama, sastra lisan Jawa telah menyedot perhatian orang. Karena itu, sastra lisan dipandang memeliki keunikan. Dilihat dari aspek bentuk maupun kandungan makna, sastra lisan memiliki perbedaan dengan sastra tulis. Peranan sastra lisan dalam pembentukan budaya masyarakat Jawa sangat menonjol. Karena sastra lisan jawa merupakan warisan leluhur, di dalamnya tertanam pesan leluhur yang istimewa. Dengan demikian, kekuatan sastra lisan Jawa memang benar-benar memberikan efek filosofis yang mendalam bagi masyarakat Jawa (sebagai masyarakat kolektif)

Sastra lisan Jawa sangatlah penting dalam kaitannya dengan pembentukan karakter pada anak siswa/siswi di sekolah. Karena itu, diharapkan, ada sinergi antara guru, murid, masyarakat, dan penentu kebijakan dalam kaitannya dengan pembelajaran sastra lisan di sekolah. Jika sastra lisan Jawa diajarkan di sekolah, anak-anak akan mengenal secara implisit/eksplisit representasi pendidikan karakter yang ada di sekolah. Dengan demikian, akan terbentuk karakter yang cerdas, beretika, dan beriman. 


\section{DAFTAR PUSTAKA}

Ahmadi, Anas. Pembelajaran Sastra Lisan Jawa di Sekolah sebagai Alternatif Pembentukan Karakter. Artikel Dosen Bahasa dan Sastra Indonesia, Universitas Negeri Surabaya.

Amir, Adriyetti. 2013. Sastra Lisan Indonesia. Yogyakarta: ANDI.

Endraswara, E. 2005. Tradisi Lisan Jawa. Yogyakarta: Narasi.

Rosidi, Ajib. 1995. Sastra dan Budaya: Kedaerahan dalam Keindonesian. Yogyakarta: Pustaka Pelajar.

Soehardi. Nilai-nilai Tradisi Lisan dalan Budaya Jawa. Jurnal Media Pendidikan dan Ilmu Pengetahuan 20 (10):1-10. 